\title{
Digitalislike Compounds Restore hNIS Expression and Iodide Uptake Capacity in Anaplastic Thyroid Cancer
}

\author{
Marika H. Tesselaar ${ }^{1}$, Thomas Crezee ${ }^{1}$, Imke Schuurmans ${ }^{1}$, Danny Gerrits ${ }^{2}$, James Nagarajah ${ }^{2}$, Otto C. Boerman ${ }^{2}$, \\ Ilse van Engen-van Grunsven ${ }^{1}$, Johannes W.A. Smit ${ }^{3}$, Romana T. Netea-Maier ${ }^{3}$, and Theo S. Plantinga ${ }^{1}$ \\ ${ }^{I}$ Department of Pathology, Radboud University Medical Center and Radboud Institute for Molecular Life Sciences, Nijmegen, The \\ Netherlands; ${ }^{2}$ Department of Radiology and Nuclear Medicine, Radboud University Medical Center and Radboud Institute for \\ Molecular Life Sciences, Nijmegen, The Netherlands; and ${ }^{3}$ Department of Internal Medicine, Radboud University Medical Center and \\ Radboud Institute for Molecular Life Sciences, Nijmegen, The Netherlands
}

Anaplastic thyroid cancer (ATC) is a rare malignancy that accounts for $1 \%-2 \%$ of all thyroid cancers. ATC is one of the most aggressive human cancers, with rapid growth, tumor invasion, and development of distant metastases. The median survival is only $5 \mathrm{mo}$, and the $1-y$ survival is less than $20 \%$. Moreover, as a result of severe dedifferentiation, including the loss of human sodium iodide symporter (hNIS) expression, radioactive iodide (RAl) therapy is ineffective. Recently, we have demonstrated beneficial effects of autophagy-activating digitalislike compounds (DLCs) on redifferentiation and concomitant restoration of iodide uptake in RAlrefractory papillary and follicular thyroid cancer cell lines. In the current study, the effects of DLCs on differentiation and proliferation of ATC cell lines were investigated. Methods: Autophagy activity was assessed in ATC patient tissues by immunofluorescent staining for the autophagy marker microtubule-associated protein 1A/1B-light chain 3 (LC3). In addition, the effect of autophagyactivating DLCs on the proliferation, gene expression profile, and iodide uptake capacity of ATC cell lines was studied. Results: Diminished autophagy activity was observed in ATC tissues, and in vitro treatment of ATC cell lines with DLCs robustly restored hNIS and thyroglobulin expression and iodide uptake capacity. In addition, proliferation was strongly reduced by induction of cell cycle arrest and, to some extent, cell death. Mechanistically, reactivation of functional hNIS expression could be attributed to activation of the transcription factors activating transcription factor 3 and protooncogene c-fos. Conclusion: DLCs could represent a promising adjunctive therapy for restoring iodide avidity within the full spectrum from RAI-refractory dedifferentiated to ATC.

Key Words: anaplastic thyroid cancer; autophagy; digitalislike compounds; hNIS; radioactive iodide

J Nucl Med 2018; 59:780-786

DOI: 10.2967/jnumed.117.200675

\section{A} naplastic thyroid cancer (ATC) is a rare type of nonmedullary thyroid cancer (TC) that accounts for $1 \%-2 \%$ of all thyroid malignancies. ATC is one of the most aggressive human cancers,

Received Aug. 14, 2017; revision accepted Oct. 18, 2017.

For correspondence or reprints contact: Theo S. Plantinga, Department of Pathology, Radboud University Medical Center, Geert Grooteplein Zuid 10, 6500 HB Nijmegen, The Netherlands.

E-mail: theo.plantinga@radboudumc.nl

Published online Dec. 14, 2017.

COPYRIGHT (C 2018 by the Society of Nuclear Medicine and Molecular Imaging. with rapid growth, local tumor invasion, and distant metastases. Despite application of different treatment modalities, including surgery, chemotherapy, and radiotherapy, the median survival is only $5 \mathrm{mo}$ and the $1-\mathrm{y}$ survival is less than $20 \%(1-3)$. Furthermore, since functional expression of human sodium iodide symporter (hNIS), normally present on the thyrocyte membrane to facilitate iodide influx, is lost as a result of cellular dedifferentiation, the tumor becomes resistant to radioactive iodide (RAI) treatment (4).

For dedifferentiated TC, restoring functional hNIS expression on the cell membrane of TC tumor cells to reactivate iodide uptake, designated redifferentiation, represents a promising therapeutic strategy, mainly because of the high tumoricidal effects of RAI. Recently, several adjunctive therapies have been identified that are capable of improving iodide accumulation in RAIrefractory tumors, including inhibitors of mitogen-activated protein kinase (MAPK)/extracellular signal-regulated kinase (ERK) (5), v-RAF murine sarcoma viral oncogene homolog B1 (BRAF) (6) or mammalian target of rapamycin (7), and autophagy-activating compounds (8). However, no published studies have addressed the redifferentiation potential of any of these compounds in ATC.

Autophagy, an important mechanism for maintaining cellular homeostasis, is activated on cellular stresses, including nutrient deprivation and hypoxia. In addition, autophagy plays a role in carcinogenesis and the dedifferentiation process and is heavily intertwined with oncogenic pathways (9-12). In a previous study, autophagy activity was assessed in patients with poorly differentiated TC tumors, either follicular or papillary TC, and was correlated with clinical outcome parameters. This study demonstrated that TC tumors with high autophagy activity were responsive to RAI therapy and that the corresponding patients were more likely to reach remission, whereas low autophagy activity was associated with poor prognosis and RAI resistance (13). Moreover, autophagyactivating compounds, particularly digitalislike compounds (DLCs) such as digoxin, have been demonstrated to inhibit proliferation and to restore functional hNIS expression and iodide uptake capacity in poorly differentiated TC cell lines. Digoxin, directly inhibiting $\mathrm{Na}^{+} / \mathrm{K}^{+}$adenosinetriphosphatase (ATPase), is currently prescribed to patients with cardiac failure and arrhythmia for its effects on cardiomyocyte contractility $(14,15)$. Interestingly, several studies have addressed the potential of DLCs, digoxin in particular, as anticancer therapy and have revealed antiproliferative and proapoptotic effects on breast cancer, prostate cancer, melanoma, pancreatic cancer, lung cancer, and leukemia (16). Taken together, activation of autophagy by DLCs to restore hNIS expression and thereby reinduce 
sensitivity to RAI treatment might be a novel therapeutic strategy for poorly differentiated TC by multifaceted actions. However, this promising capacity of DLCs remains to be addressed for ATC.

In the present study, we assessed autophagy activity in ATC tissues and investigated the effect of DLC treatment concerning inhibition of proliferation or restoration of RAI uptake in 2 different ATC cell lines with distinctive genetic profiles. Based on the previous observations, we hypothesized that activation of autophagy by DLCs leads to inhibition of proliferation and to an increased capacity for RAI uptake in ATC cell lines.

\section{MATERIALS AND METHODS}

\section{Cell Culture and Reagents}

Two ATC cell lines, 8505C and Cal-62 (kindly provided by Prof. James Fagin, Memorial Sloan Kettering Cancer Center), harboring a $B R A F^{V 600 E}$ or $K R A S^{G 12 R}$ mutation, respectively, were cultured in Dulbecco modified Eagle medium supplemented with $10 \%$ fetal calf serum, $1 \mathrm{mM}$ pyruvate, and gentamycin. Before use, the cell lines were authenticated by short tandem repeat profiling (17). The cells were incubated with dimethylsulfoxide (vehicle control); with the DLCs digoxin, strophanthin $\mathrm{K}$, lanatoside $\mathrm{C}$, digoxigenin (all from Sigma-Aldrich), or proscillaridin A (Santa Cruz Biotechnology); or with the MAPK/ERK-inhibitor selumetinib, the $B R A F^{V 600 E}$ inhibitor dabrafenib, or the mammalian-target-of-rapamycin inhibitor rapamycin (all from Sigma-Aldrich) for indicated time points and concentrations. For all compounds, stock concentrations ranged between 50 and $100 \mathrm{mM}$ in dimethylsulfoxide vehicle. Compound selection and applied concentrations were based on earlier studies $(7,8,18,19)$

\section{Light Chain 3 (LC3)-II Immunofluorescence}

To assess autophagy activity in ATC tissue specimens, fluorescent staining for the autophagy marker LC3 was performed on formalinfixed paraffin-embedded tissues derived from 10 ATC patients and compared with papillary TC cases with either low or high autophagy activity that were reported previously by our group (13). Ethical approval was obtained for the use of all patient tissues, which were obtained from the pathology archives of either Radboud University Medical Center, Nijmegen, The Netherlands, or collaborating pathology laboratories elsewhere in The Netherlands. LC3-II immunofluorescent 4',6-diamidino-2-phenylindole staining was performed as described previously (13). Staining was examined by a fluorescent microscope (DMI6000B; Leica). Autophagy activity was assessed by quantifying, using Fiji software, the number of LC3-II-positive puncta, representing LC3 incorporated in the autophagosomal membrane, per 100 cell nuclei. Scoring results were generated in quintuplet for each tissue section.

\section{Real-Time Quantitative PCR}

To investigate the potential capacity of autophagy activation by DLCs for reactivation of hNIS expression, the ATC cell lines Cal-62 and $8505 \mathrm{C}$ were treated for 24,48 , and $72 \mathrm{~h}$ with $5-50 \mu \mathrm{M}$ concentrations of the DLCs digoxin, strophanthin $\mathrm{K}$, lanatoside $\mathrm{C}$, digoxigenin, and proscillaridin A. In addition, both cell lines were treated with other previously identified TC redifferentiation agents: the MAPK/ ERK kinase inhibitor selumetinib (5), the mammalian-target-of-rapamycin inhibitor rapamycin (7), $8505 \mathrm{C}$ specifically with the selective $B R A F^{V 600 E}$ inhibitor dabrafenib, or vehicle control (6). The treated ATC cell lines were lysed with TRIzol reagent (Invitrogen) followed by total RNA purification performed according to the manufacturer's instructions. iScript complementary DNA synthesis kits (Bio-Rad Laboratories) were used to transcribe isolated RNA into complementary DNA. Subsequently, quantitative PCR was performed using the SYBR Green method (Life Technologies). The primers used are listed in Supplemental Table 1 (supplemental materials are available at http://jnm. snmjournals.org).

\section{Western Blotting}

Western blotting of hNIS protein was performed as described previously $(8)$. Cells $\left(5 \times 10^{6}\right)$ were lysed in $40 \mu \mathrm{L}$ of lysis buffer (radioimmunoprecipitation assay buffer; Cell Signaling Technology). The membrane was blocked in Odyssey blocking buffer (Westburg) plus tris-buffered saline (TBS)/0.1\% polysorbate 20 (1:1), followed by an overnight incubation at $4{ }^{\circ} \mathrm{C}$ with a rabbit-antihuman hNIS antibody (1:500, 250552; Abbiotec) or a mouse-antihuman glyceraldehyde 3-phosphate dehydrogenase antibody (loading control, 1:10,000, ab8245; Abcam) in Odyssey blocking buffer plus TBS/0.1\% polysorbate 20 (1:1). After overnight incubation, the membranes were washed with TBS $/ 0.1 \%$ polysorbate 20 and incubated with goat-antirabbit 688 or goat-antimouse 688 for $1 \mathrm{~h}$ at room temperature. After being washed with TBS/ $0.1 \%$ polysorbate 20 , membranes were analyzed by an Odyssey imager (Westburg).

\section{Cell Proliferation and Viability Assays}

For measurement of proliferation, 3-(4,5-dimethylthiazol-2-yl)-2,5diphenyltetrazolium bromide (MTT) assays were performed according to the manufacturer's instructions (Sigma-Aldrich). In brief, cells $(1 \times$ $10^{3}$ ) were incubated with the DLCs for the indicated time points and concentrations. Subsequently, MTT substrate was added and the amount of converted substrate was measured by a plate reader at $570 \mathrm{~nm}$. At first, the effects of DLCs on proliferation, cell survival, and cell cycle arrest were assessed. Separate MTT assays were performed at 24, 48, and $72 \mathrm{~h}$ after treatment with the selected DLCs at the indicated concentrations.

In addition, to determine whether inhibition of proliferation is attributable to induction of cell death, lactate dehydrogenase activity was measured in cell culture supernatants at the same time points for assessment of cell death in accordance with the suppliers' protocol (CytoTox 96 kit; Promega).

\section{In Vitro lodide Uptake}

To determine whether increased expression of hNIS generates functional protein expression enabling iodide influx, in vitro ${ }^{125} \mathrm{I}$ iodide uptake assays were performed as described previously $(8,20)$. The ATC cell lines were treated for $48 \mathrm{~h}$ with one of the selected DLCs, at a $50 \mu \mathrm{M}$ concentration. Subsequently, to determine the hNIS specific uptake of RAI, the cells were incubated for 30 min with $2.5 \mathrm{kBq}$ of $\mathrm{Na}^{125} \mathrm{I} / \mathrm{mL}$ (Perkin-Elmer) and $20 \mu \mathrm{M}$ nonradioactive NaI as a carrier, with or without the competitive hNIS inhibitor sodium perchlorate, $80 \mu \mathrm{M}$, to control for hNIS-specific uptake. Radioactive medium was aspirated, and the cells were washed with ice-cold phosphate-buffered saline and lysed in $0.1 \mathrm{M} \mathrm{NaOH}$ buffer. Radioactivity was measured in the cell lysates in an automatic $\gamma$-counter (Wizard ${ }^{2}$; Perkin-Elmer). In parallel experiments, DNA was isolated from the cells (Puregene kit; Gentra Systems) and quantified by Nanodrop measurements (Thermo Fisher Scientific). Accumulated radioactivity was expressed as cpm per milligram of DNA.

\section{Gene Expression Profiling of ATC Cell Lines after Treatment with DLCs}

To elucidate the mechanism behind hNIS upregulation in ATC cell lines by DLCs, messenger RNA expression of thyroid-stimulating hormone receptor, thyroid transcription factor 1 , thyroid transcription factor 2, paired box gene 8, activating transcription factor 3 (ATF3), and proto-oncogene c-fos (cFOS) was measured. In addition, expression of thyroglobulin and thyroid peroxidase was measured. 


\section{Statistical Analysis}

Statistical significance was tested with the Student $t$ test, MannWhitney $U$ test, Spearman rank correlation coefficient, or Wilcoxon matched-pairs signed-rank test, when appropriate. $P$ values below 0.05 were considered statistically significant. All statistical tests were performed using GraphPad Prism, version 5.0.

\section{RESULTS}

\section{Autophagy Activity Is Diminished in ATC Tissues}

All analyzed ATC tissue specimens exhibited low autophagy activity as demonstrated by the respective images of fluorescent LC3 staining (Fig. 1A), as well as by quantification of the number of LC3-II-positive puncta in ATC tumor cells (Fig. 1B).

\section{DLCs Inhibit Proliferation and Induce Cell Death and Cell Cycle Arrest in ATC Cell Lines}

All DLCs potently inhibited proliferation at and above concentrations of either $0.05,0.5$, or $5 \mu \mathrm{M}$ in both cell lines (Supplemental Fig. 1A). After $24 \mathrm{~h}$ of treatment, up to $37 \%$ of total lactate dehydrogenase was released by $8505 \mathrm{C}$ cells in a dose-dependent manner. The highest percentage of cell death was after treatment with $50 \mu \mathrm{M}$ proscillaridin A. For Cal-62, a dose-dependent increase in lactate dehydrogenase release was observed after incubation with digoxin and strophanthin $\mathrm{K}$. Lanatoside $\mathrm{C}$, digoxigenin, and proscillaridin $\mathrm{A}$ also induced lactate dehydrogenase release in the Cal-62 cell line, but largely independent of the administered dose

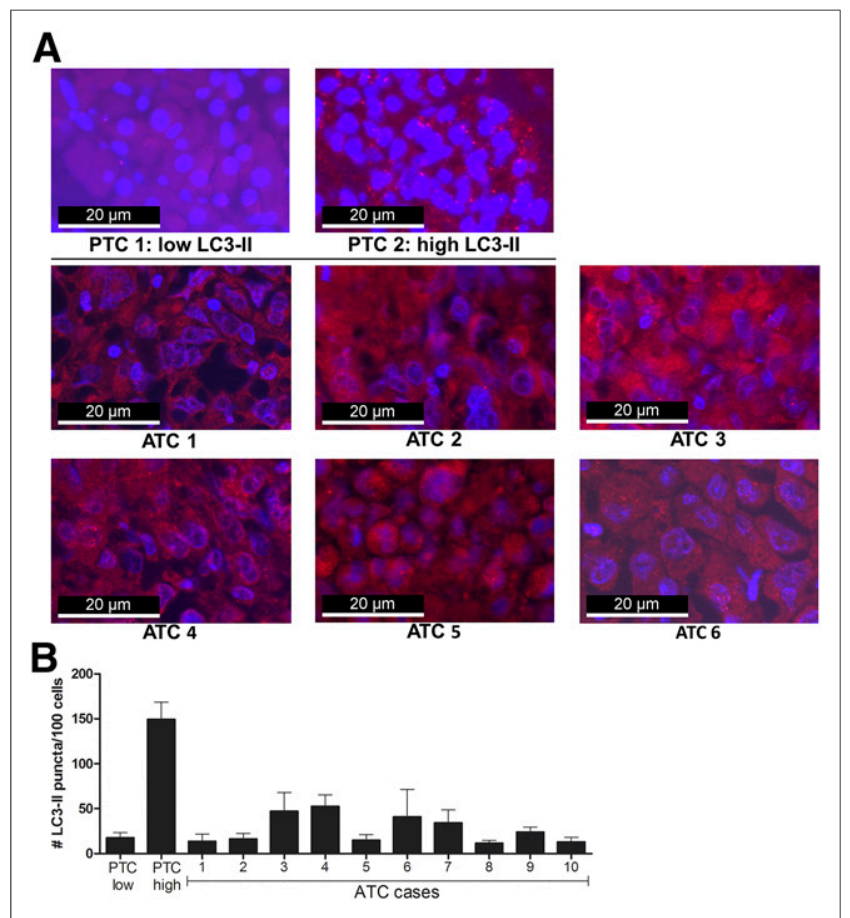

FIGURE 1. Autophagy activity in ATC tissues. (A) LC3-II immunofluorescent staining of formalin-fixed paraffin-embedded ATC specimens (1-6) and 2 papillary thyroid carcinomas with either low or high autophagy activity. LC3-II-positive puncta were visualized by fluorescent microscopy; cells were counterstained with 4',6-diamidino-2-phenylindole. (B) Autophagy activity in ATC tissues. Quantification of number of LC3-IIpositive puncta per 100 cells in papillary TC (PTC) control tissues and ATC tissues of all 10 patients. Data are based on 2 independent experiments, and images were analyzed in quintuplet. LC3-II = lipidated form of microtubule-associated protein 1A/1B LC3B.
(Supplemental Fig. 1B). The observation that $60 \%-90 \%$ of cells survived after DLC treatment for $48 \mathrm{~h}$ and that proliferation was completely inhibited in surviving cells indicated that these cells could have undergone cell cycle arrest. To provide additional arguments for this possibility, CDKN1A/p21 gene expression analysis was performed. Expression of CDKN1A/p21 was increased in both $8505 \mathrm{C}$ and Cal-62 after DLC treatment; the highest upregulation was observed in $8505 \mathrm{C}$ after 48 or $72 \mathrm{~h}$ of treatment, whereas in Cal-62 the highest upregulation was apparent after $72 \mathrm{~h}$ of treatment (Supplemental Fig. 1C).

\section{DLCs Restore hNIS Expression in ATC Cell Lines}

The diminished autophagy activity that was observed in ATC tissue sections uncovered a compelling opportunity to investigate the potential capacity of autophagy activation by DLCs for reactivation of hNIS expression. Whereas none of the targeted kinase inhibitors were able to induce hNIS expression, all tested DLCs were capable of reactivating hNIS messenger RNA expression in both cell lines, in most cases in a dose-dependent manner. In $8505 \mathrm{C}$, the highest hNIS upregulation was observed at the 24- and 48-h time points; however, in Cal-62 the highest hNIS upregulation was maximally induced at 48 and $72 \mathrm{~h}$ (Fig. 2A). In addition, most DLCs induced hNIS protein expression after $48 \mathrm{~h}$ of treatment, except for digoxigenin-treated cells. Protein expression of nonglycosylated hNIS (56 kDa) and dimerized nonglycosylated hNIS (120 kDa) was especially elevated, whereas levels of the glycosylated monomer isoform $(87 \mathrm{kDa})$ were increased to a lesser extent. Notably, in digoxin-treated $8505 \mathrm{C}$ solely increased expression of nonglycosylated hNIS was observed (Fig. 2B).

\section{lodide Uptake in ATC Cell Lines Is Restored by DLCs}

In both $8505 \mathrm{C}$ and Cal-62, iodide uptake was strongly increased after treatment with digoxin, strophanthin $\mathrm{K}$, and lanatoside $\mathrm{C}$. In all these conditions, iodide uptake was efficiently inhibited by sodium perchlorate. In contrast, after treatment with proscillaridin A or digoxigenin, no increased RAI uptake was observed in the 2 ATC cell lines (Fig. 2C).

\section{Expression of Some Genes in ATC Cell Lines Is Altered After Treatment with DLCs}

No expression of thyroid-stimulating hormone receptor or thyroid peroxidase was observed in either cell line (data not shown). In 8505C, expression of thyroid transcription factor 1 and paired box gene 8 was not affected by DLC treatment. In contrast, expression of thyroid transcription factor 2 in $8505 \mathrm{C}$ and expression of paired box gene 8 and thyroid transcription factors 1 and 2 in Cal-62 were increased in some conditions, but this increased expression was not clearly associated with the degree of induced hNIS expression. In both $8505 \mathrm{C}$ and Cal62, increased thyroglobulin expression was observed after treatment with all DLCs (Fig. 3A). Interestingly, ATF3 and cFOS expression increased after DLC treatment and both were highly associated with the increased hNIS expression at all 3 time points in both cell lines (Fig. 3B).

\section{DISCUSSION}

ATC is a rare and devastating malignancy characterized by rapid proliferation, invasion, and dissemination. Patients diagnosed with ATC often present with inoperable locally advanced disease and have a poor prognosis with a median survival of only 5 mo and a 1-y survival rate of $20 \%(1,2)$. Genetic studies have 

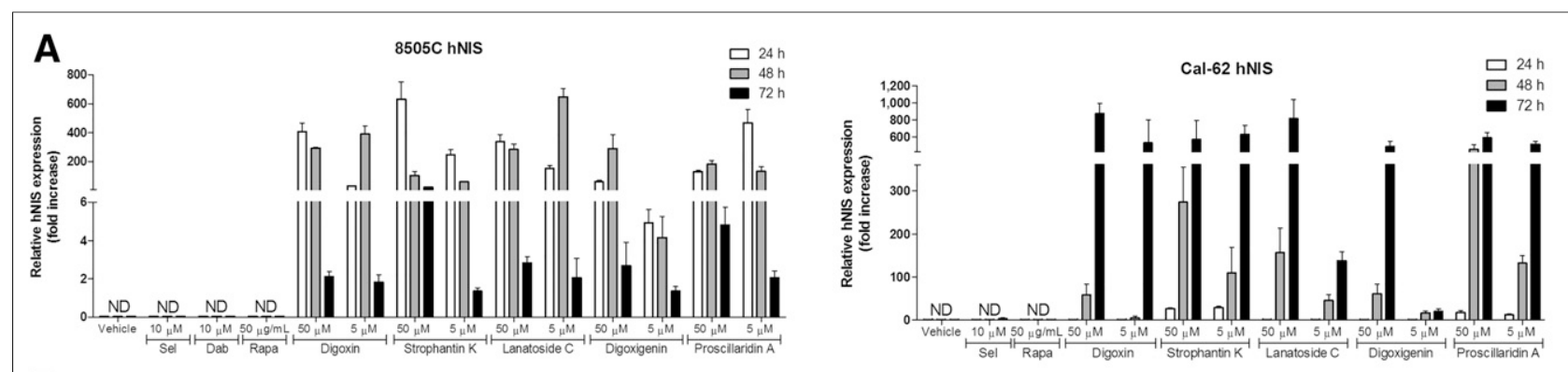

B

\section{$8505 \mathrm{C}$}
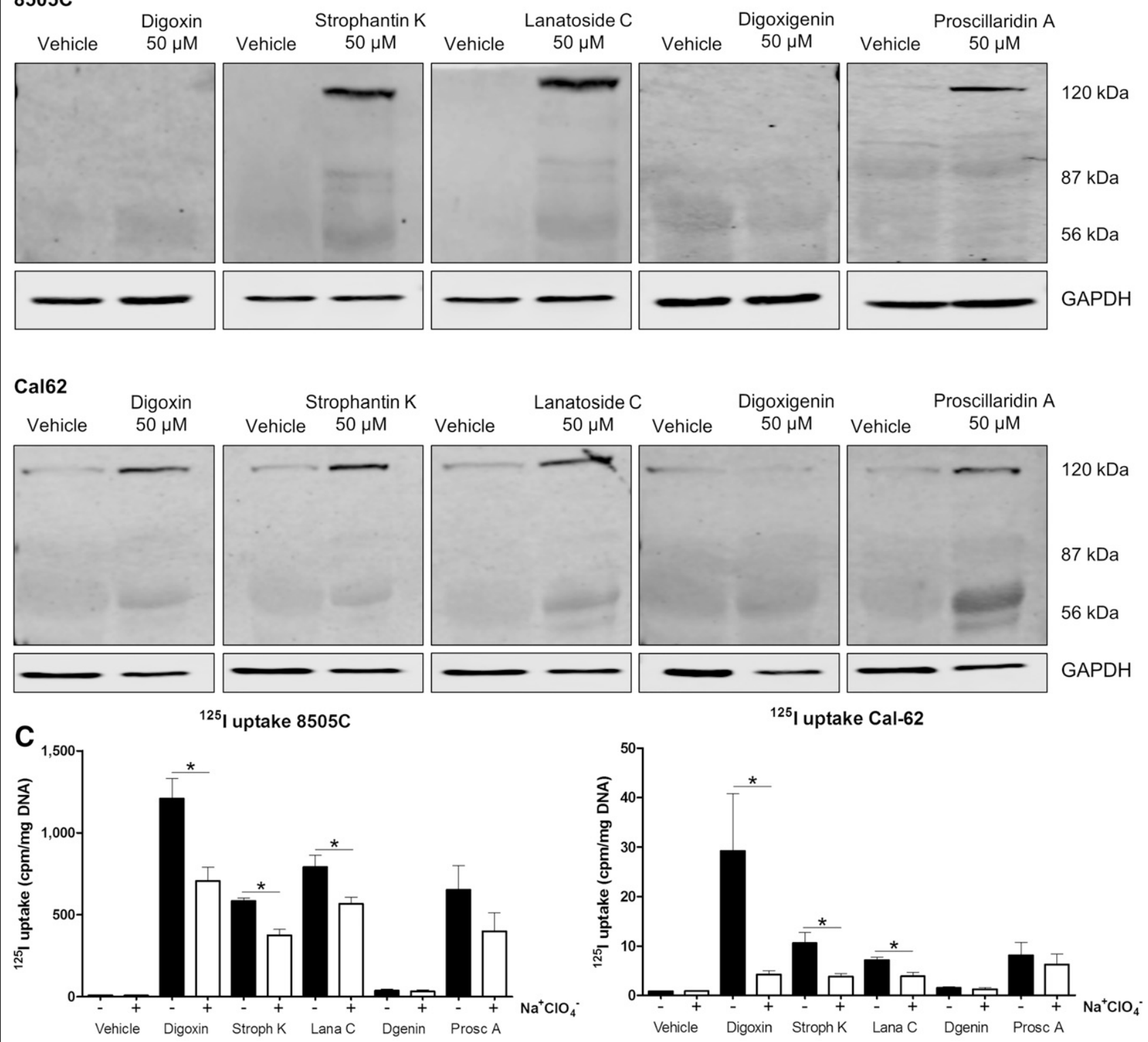

FIGURE 2. hNIS messenger RNA and protein expression and iodide uptake induced by digitalislike compounds. (A) hNIS messenger RNA expression in ATC cell lines $8505 \mathrm{C}$ and Cal-62 after 24,48 , and $72 \mathrm{~h}$ of treatment with selumetinib $(10 \mu \mathrm{M})$, dabrafenib $(10 \mu \mathrm{M})$, or rapamycin $(50 \mu \mathrm{g} / \mathrm{mL})$ or with $5 \mu \mathrm{M} / 50 \mu \mathrm{M}$ of the indicated digitalislike compounds. Data are mean \pm SD. (B) hNIS protein expression in ATC cell lines $8505 \mathrm{C}$ and Cal-62 after treatment with $50 \mu \mathrm{M}$ of the indicated digitalislike compounds for $48 \mathrm{~h}$. Data are representative of 3 independent experiments. (C) ${ }^{125}$-iodide uptake by ATC cell lines $8505 \mathrm{C}$ and Cal-62 after treatment with $50 \mu \mathrm{M}$ of the indicated digitalislike compounds with or without the competitive hNIS inhibitor sodium perchlorate $\left(\mathrm{Na}^{+} \mathrm{ClO}_{4}{ }^{-}\right)$. Data are mean $\pm \mathrm{SD}(n=6)$. ${ }^{\star} P<0.05$. ND $=$ not detectable; Sel $=$ selumetinib; $\mathrm{Dab}=$ dabrafenib; Rapa = rapamycin; Stroph $\mathrm{K}=$ strophantin $\mathrm{K}$; Lana $\mathrm{C}=$ lanatoside $\mathrm{C}$; Dgenin = digoxigenin; Prosc $\mathrm{A}=$ proscillaridin $\mathrm{A}$. 


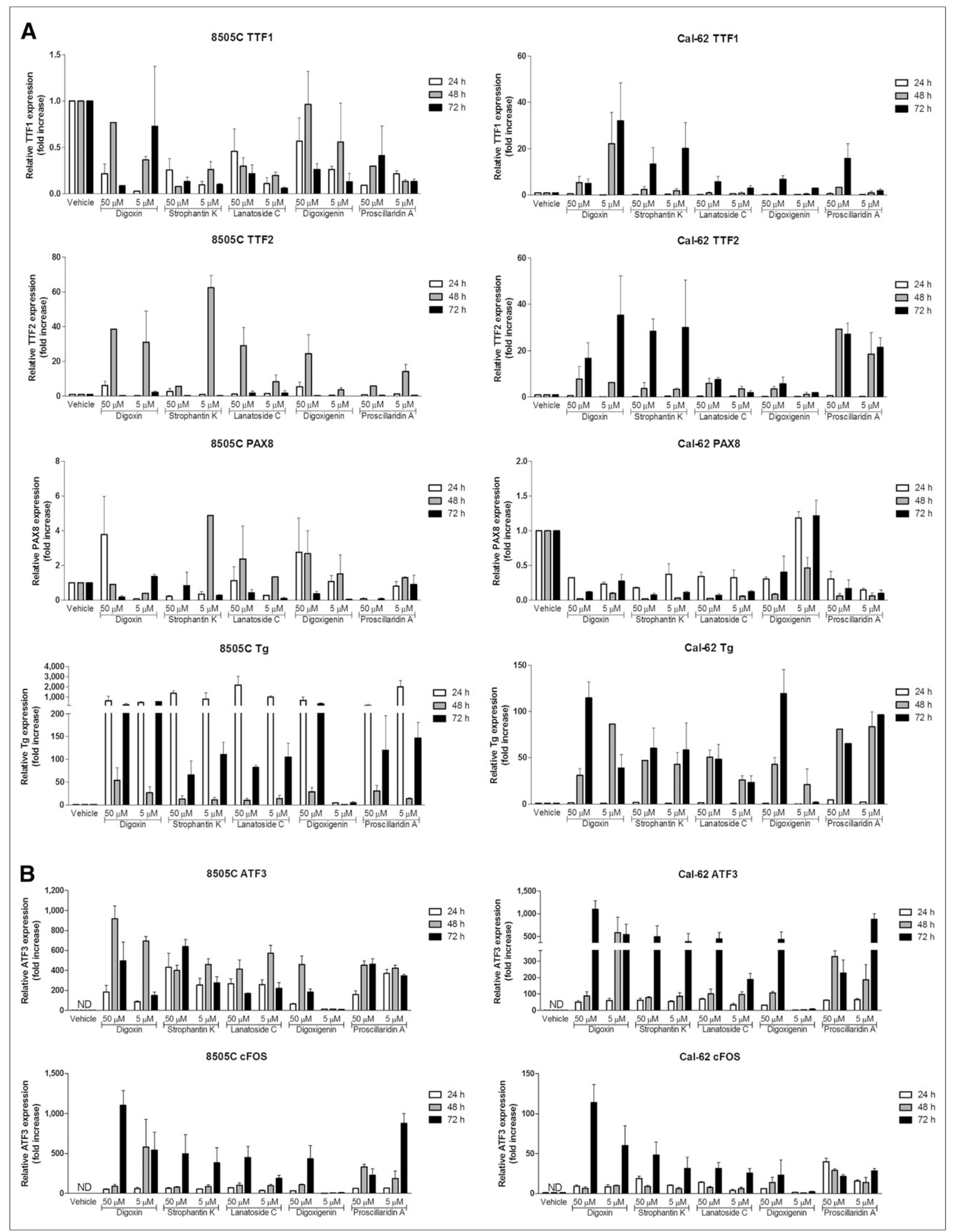

FIGURE 3. Gene expression profiling of ATC cell lines after treatment with digitalislike compounds. (A) TTF1, TTF2, and PAX8 and thyroglobulin $(\mathrm{Tg})$ messenger RNA expression in ATC cell lines $8505 \mathrm{C}$ and Cal-62 after treatment with digitalislike compounds $(5 \mu \mathrm{M}$ or $50 \mu \mathrm{M})$ for 24,48 , and $72 \mathrm{~h}$. Data are mean \pm SD. (B) ATF3 and cFOS messenger RNA expression in ATC cell lines $8505 \mathrm{C}$ and Cal-62 after 24, 48, and $72 \mathrm{~h}$ of treatment with digitalislike compounds $(5 \mu \mathrm{M}$ or $50 \mu \mathrm{M})$. Data are mean \pm SD. 
revealed that ATC mostly originates from preexisting papillary TC with $B R A F$ or $R A S$ driver mutations, which have subsequently evolved toward ATC by acquiring additional genetic aberrations, particularly in TP53, PIK3CA, and TERT promoter $(21,22)$. Despite recent insights into the etiology of ATC, currently no curative treatment options are available.

Conventional treatment of well-differentiated TC includes thyroidectomy followed by RAI ablation of tumor remnants (23). The response to RAI therapy highly depends on an intact iodide metabolism in which functional expression of hNIS, normally present at the basal membrane of thyroid follicular cells, is crucial. Currently, RAI therapy is not eligible for ATC patients, since tumor cells have lost their thyroid-specific gene expression related to iodide metabolism, leading to RAI refractoriness $(4,24)$.

For poorly differentiated TC, novel therapeutic strategies have recently emerged that facilitate redifferentiation of tumor cells, thereby increasing their capacity for RAI uptake (5-8,25). Previously, loss of autophagy activity was shown to be associated with RAI resistance in dedifferentiated TC (13). Here, by assessment of autophagy activity in ATC tissue specimens, it was demonstrated that also in ATC tumor cells autophagy activity is clearly diminished. Considering the beneficial effects of autophagy activation observed in dedifferentiated $\mathrm{TC}$, these similar findings in ATC specimens provide a compelling opportunity to study the effects of autophagy activation on ATC proliferation and differentiation.

Accordingly, the present study revealed that autophagy activation by DLCs such as digoxin, also designated as cardiac glycosides, enables reactivation of hNIS expression and iodide uptake in ATC cell lines. Although the targeted kinase inhibitors selumetinib, dabrafenib, and rapamycin, previously described as facilitating redifferentiation of RAI-refractory papillary and follicular TC, were not able to induce hNIS expression in ATC, several DLC analogs (at $5 \mu \mathrm{M}$ and $50 \mu \mathrm{M}$ concentrations) were demonstrated to reactivate hNIS expression and restore iodide uptake capacity in 2 ATC cell lines with different genetic backgrounds, that is, $B R A F^{V 600 E_{-}}$and TP53-driven $(8505 \mathrm{C})$ and $K R A S^{G 12 R_{-}}$and TP53-driven (Cal-62). As observed for dedifferentiated TC cell lines, similar intracellular mechanisms are activated by DLCs, including upregulation of early response genes ATF3 and cFOS, inhibition of proliferation and induction of cell cycle arrest and, to a lesser extent, cell death. Importantly, expression of the thyroid-specific transcription factors paired box gene 8 and thyroid transcription factors 1 and 2 was largely unaffected by DLC treatment, indicating their less pronounced role in restoring DLC-induced hNIS expression. In addition, expression of thyroglobulin increased after treatment with all DLCs in the 2 ATC cell lines, whereas expression of thyroid-stimulating hormone receptor and thyroid peroxidase remained undetectable. This finding indicates that the molecular machinery for iodide metabolism is partly restored by DLC treatment.

All DLC analogs used in this study, except digoxigenin, induced hNIS protein expression that was predictive for RAI uptake in both cell lines. Several hNIS protein isoforms were detected after DLC treatment: the 56-kDa nonglycosylated and $87-\mathrm{kDa}$ glycosylated monomer isoforms and, with highest intensity, $120-\mathrm{kDa}$ nonglycosylated hNIS dimers. Although the molecular characteristics and biologic relevance of hNIS dimerization are unclear, the occurrence and functionality of dimers and higher multimers has been described before in hNIS transfection studies and were shown to depend on the formation of disulfide bridges (26-28).
Of note, only the nonglycosylated monomeric form of the hNIS protein was induced after treatment of the $8505 \mathrm{C}$ cell line with digoxin, nevertheless facilitating increased iodide uptake comparable to the other DLC analogs. These findings suggest a relatively minor contribution of hNIS dimers in total iodide uptake capacity.

In contrast to dedifferentiated TC, redifferentiation agents inhibiting either MAPK/ERK, BRAF, or mammalian-target-ofrapamycin kinases were not capable of restoring functional hNIS expression in ATC cell lines. This observation could be explained by the multiple oncogenic pathways driving ATC in addition to constitutive BRAF/KRAS kinase activity, particularly caused by loss-of-function mutations in the tumor suppressor p53. Consequently, by inhibition of a single oncogenic pathway, others remain unaffected, and the intracellular processes driving proliferation and dedifferentiation are largely retained. In contrast, DLC treatment could modulate several intracellular signaling pathways in ATC cell lines simultaneously by activating intracellular $\mathrm{Ca}^{2+}$ signaling and downstream pathways, including autophagy, thereby robustly counteracting the ATC tumor phenotype.

Digoxin is a clinically used $\mathrm{Na}^{+} / \mathrm{K}^{+}$ATPase inhibitor, inhibiting $\mathrm{K}^{+}$influx and $\mathrm{Na}^{+}$efflux for treatment of cardiac failure and arrhythmia. On $\mathrm{Na}^{+} / \mathrm{K}^{+}$ATPase inhibition, intracellular $\mathrm{Na}^{+}$concentrations rise, evoking passive exchange of intracellular $\mathrm{Na}^{+}$for extracellular $\mathrm{Ca}^{2+}$ through the $\mathrm{Na}^{+} / \mathrm{Ca}^{2+}$ exchanger (NCX), ultimately leading to elevated intracellular $\mathrm{Ca}^{2+}$ concentrations. It is well established that intracellular $\mathrm{Ca}^{2+}$ acts as a second messenger and influences numerous cellular processes, including regulation of gene expression, proliferation, differentiation, migration, and apoptosis $(29,30)$. Intracellular $\mathrm{Ca}^{2+}$ activates autophagy by triggering calcineurin, ERK, adenosine monophosphate-activated protein kinase, and the transcription factor $\operatorname{EB}(31,32)$. In addition, intracellular signaling is activated that partly resembles the thyroidstimulating hormone receptor pathway, involving cyclic adenosine monophosphate and its response-element-binding protein $(33,34)$. Eventually, this process leads to activation of early-response genes ATF3 and cFOS, both transcription factors that are known to drive hNIS expression by triggering the CRE-like sequence of the hNIS upstream enhancer in cooperation with the thyroid-specific transcription factor paired box gene $8(35,36)$.

Other previously reported efforts to restore functional hNIS expression in ATC comprise hNIS upregulation by gene transduction and, pharmacologically, by the use of histone deacetylase inhibitors or estrogen-related receptor $\gamma$-antagonists $(37,38)$. It remains to be established whether combination therapies targeting $\mathrm{Na}^{+} / \mathrm{K}^{+}$ATPases, histone deacetylases, and estrogen-related receptor $\gamma$ induce synergistic effects on hNIS expression and iodide uptake in ATC.

\section{CONCLUSION}

Taken together, $\mathrm{Na}^{+} / \mathrm{K}^{+}$ATPase inhibition by DLCs restores functional hNIS expression and the capacity for iodide uptake in ATC cell lines. Confirmation of these findings in mouse models and human studies is warranted. In addition, concerning the narrow therapeutic index of DLCs and the notion that the required DLC concentration for in vitro redifferentiation $(5 \mu \mathrm{M})$ exceeds the maximally tolerated dose in humans, future studies should address the dosage required for restoring functional hNIS in ATC in vivo in relation to its toxicity. DLCs could represent a 
promising adjunctive therapy for restoring iodide avidity within the full spectrum from RAI-refractory dedifferentiated to ATC.

\section{DISCLOSURE}

Theo S. Plantinga was supported by a Veni grant from the Netherlands Organization for Scientific Research (NWO; 016.136.065) and by the Alpe d'HuZes fund of the Dutch Cancer Society (KUN2014-6728). No other potential conflict of interest relevant to this article was reported.

\section{REFERENCES}

1. Smallridge RC, Copland JA. Anaplastic thyroid carcinoma: pathogenesis and emerging therapies. Clin Oncol (R Coll Radiol). 2010;22:486-497.

2. Cabanillas ME, McFadden DG, Durante C. Thyroid cancer. Lancet. 2016;388: 2783-2795.

3. Smallridge RC, Ain KB, Asa SL, et al. American Thyroid Association guidelines for management of patients with anaplastic thyroid cancer. Thyroid. 2012;22:1104-1139.

4. Xing M. Molecular pathogenesis and mechanisms of thyroid cancer. Nat Rev Cancer. 2013;13:184-199.

5. Ho AL, Grewal RK, Leboeuf R, et al. Selumetinib-enhanced radioiodine uptake in advanced thyroid cancer. $N$ Engl J Med. 2013;368:623-632.

6. Rothenberg SM, McFadden DG, Palmer EL, Daniels GH, Wirth LJ. Redifferentiation of iodine-refractory braf v600e-mutant metastatic papillary thyroid cancer with dabrafenib. Clin Cancer Res. 2015;21:1028-1035.

7. Plantinga TS, Heinhuis B, Gerrits D, et al. Mtor inhibition promotes ttf1-dependent redifferentiation and restores iodine uptake in thyroid carcinoma cell lines. J Clin Endocrinol Metab. 2014;99:E1368-E1375.

8. Tesselaar MH, Crezee T, Swarts HG, et al. Digitalis-like compounds facilitate non-medullary thyroid cancer redifferentiation through intracellular ca $2+$, fos, and autophagy-dependent pathways. Mol Cancer Ther. 2017;16:169-181.

9. Carnero A, Garcia-Mayea Y, Mir C, Lorente J, Rubio IT, LLeonart ME. The cancer stem-cell signaling network and resistance to therapy. Cancer Treat Rev. 2016;49:25-36.

10. Choi AM, Ryter SW, Levine B. Autophagy in human health and disease. $N$ Engl J Med. 2013;368:651-662.

11. Hönscheid P, Datta K, Muders MH. Autophagy: detection, regulation and its role in cancer and therapy response. Int J Radiat Biol. 2014;90:628-635.

12. White E. The role for autophagy in cancer. J Clin Invest. 2015;125:42-46.

13. Plantinga TS, Tesselaar MH, Morreau H, et al. Autophagy activity is associated with membranous sodium iodide symporter expression and clinical response to radioiodine therapy in non-medullary thyroid cancer. Autophagy. 2016;12: 1195-1205

14. Hauptman PJ, Garg R, Kelly RA. Cardiac glycosides in the next millennium. Prog Cardiovasc Dis. 1999;41:247-254.

15. Rahimtoola SH. Digitalis therapy for patients in clinical heart failure. Circulation. 2004;109:2942-2946.

16. Prassas I, Diamandis EP. Novel therapeutic applications of cardiac glycosides. Nat Rev Drug Discov. 2008;7:926-935.

17. Schweppe RE, Klopper JP, Korch C, et al. Deoxyribonucleic acid profiling analysis of 40 human thyroid cancer cell lines reveals cross-contamination resulting in cell line redundancy and misidentification. J Clin Endocrinol Metab. 2008; 93:4331-4341.

18. Hundeshagen P, Hamacher-Brady A, Eils R, Brady NR. Concurrent detection of autolysosome formation and lysosomal degradation by flow cytometry in a highcontent screen for inducers of autophagy. BMC Biol. 2011;9:38.
19. Shaw SY, Tran K, Castoreno AB, et al. Selective modulation of autophagy, innate immunity, and adaptive immunity by small molecules. ACS Chem Biol. 2013;8:2724-2733.

20. Hou P, Bojdani E, Xing M. Induction of thyroid gene expression and radioiodine uptake in thyroid cancer cells by targeting major signaling pathways. J Clin Endocrinol Metab. 2010;95:820-828.

21. Landa I, Ibrahimpasic T, Boucai L, et al. Genomic and transcriptomic hallmarks of poorly differentiated and anaplastic thyroid cancers. J Clin Invest. 2016;126: $1052-1066$.

22. Nikiforov YE. Genetic alterations involved in the transition from well-differentiated to poorly differentiated and anaplastic thyroid carcinomas. Endocr Pathol. 2004; $15: 319-327$.

23. Haugen BR, Alexander EK, Bible KC, et al. 2015 American Thyroid Association management guidelines for adult patients with thyroid nodules and differentiated thyroid cancer: the American Thyroid Association guidelines task force on thyroid nodules and differentiated thyroid cancer. Thyroid. 2016;26:1-133.

24. Papp S, Asa SL. When thyroid carcinoma goes bad: a morphological and molecular analysis. Head Neck Pathol. 2015;9:16-23.

25. Nagarajah J, Le M, Knauf JA, et al. Sustained erk inhibition maximizes responses of brafv600e thyroid cancers to radioiodine. J Clin Invest. 2016;126: 4119-4124.

26. Darrouzet E, Lindenthal S, Marcellin D, Pellequer JL, Pourcher T. The sodium/ iodide symporter: state of the art of its molecular characterization. Biochim Biophys Acta. 2014;1838:244-253.

27. Eskandari S, Loo DD, Dai G, Levy O, Wright EM, Carrasco N. Thyroid Na+/Isymporter: mechanism, stoichiometry, and specificity. J Biol Chem. 1997;272: 27230-27238.

28. Huc-Brandt S, Marcellin D, Graslin F, et al. Characterisation of the purified human sodium/iodide symporter reveals that the protein is mainly present in a dimeric form and permits the detailed study of a native c-terminal fragment. Biochim Biophys Acta. 2011;1808:65-77.

29. Berridge MJ, Lipp P, Bootman MD. The versatility and universality of calcium signalling. Nat Rev Mol Cell Biol. 2000;1:11-21.

30. Pinto MC, Kihara AH, Goulart VA, et al. Calcium signaling and cell proliferation. Cell Signal. 2015;27:2139-2149.

31. Medina DL, Di Paola S, Peluso I, et al. Lysosomal calcium signalling regulates autophagy through calcineurin and TFEB. Nat Cell Biol. 2015;17:288-299.

32. Wang Y, Qiu Q, Shen JJ, et al. Cardiac glycosides induce autophagy in human non-small cell lung cancer cells through regulation of dual signaling pathways. Int J Biochem Cell Biol. 2012;44:1813-1824.

33. Zaballos MA, Garcia B, Santisteban P. G $\beta \gamma$ dimers released in response to thyrotropin activate phosphoinositide 3-kinase and regulate gene expression in thyroid cells. Mol Endocrinol. 2008;22:1183-1199.

34. Morshed SA, Latif R, Davies TF. Characterization of thyrotropin receptor antibodyinduced signaling cascades. Endocrinology. 2009;150:519-529.

35. Chun JT, Di Dato V, D'Andrea B, Zannini M, Di Lauro R. The CRE-like element inside the $5^{\prime}$-upstream region of the rat sodium/iodide symporter gene interacts with diverse classes of $\mathrm{b}$-Zip molecules that regulate transcriptional activities through strong synergy with Pax-8. Mol Endocrinol. 2004;18:2817-2829.

36. Ohno M, Zannini M, Levy O, Carrasco N, di Lauro R. The paired-domain transcription factor pax 8 binds to the upstream enhancer of the rat sodium/iodide symporter gene and participates in both thyroid-specific and cyclic-amp-dependent transcription. Mol Cell Biol. 1999;19:2051-2060.

37. Singh TD, Jeong SY, Lee SW, et al. Inverse agonist of estrogen-related receptor $\gamma$ enhances sodium iodide symporter function through mitogen-activated protein kinase signaling in anaplastic thyroid cancer cells. J Nucl Med. 2015;56:16901696.

38. Pugliese M, Fortunati N, Germano A, et al. Histone deacetylase inhibition affects sodium iodide symporter expression and induces ${ }^{131} \mathrm{I}$ cytotoxicity in anaplastic thyroid cancer cells. Thyroid. 2013;23:838-846. 